\title{
Descrição de novas espécies do gênero Isoctenus (Ctenidae, Aranae)
}

\section{Cínthia Ap. B. Galeriani*(Biologia - UNICAMP), Daniele Polotow Geraldo (UFSCar)}

\section{Resumo}

As aranhas-lobo-tropicais (Família Ctenidae Keyserling 1877) são mundialmente distribuídas (exceto na Antártica), sendo particularmente abundantes na região Neotropical. Dentre os 10 gêneros reconhecidos em território brasileiro, Isoctenus é composto por 15 espécies formalmente descritas. Com a descrição de 5 novas espécies em localidades distintas do território brasileiro, a partir de figuras, medidas e caracteres diagnósticos, o gênero Isoctenus passará a conter 20 espécies. Assim, o projeto visa promover maior conhecimento taxonômico acerca da diversidade de aracnídeos presentes no Brasil.

\section{Palavras-chave:}

Sistemática, Aranhas, Neotropical.

\section{Introdução}

A família Ctenidae (Keyserling, 1877), é composta por 525 espécies distribuídas em 47 gêneros. Conhecidos como aranhas-lobo-tropicais, são predadores noturnos de pequeno a médio porte $(4.0-40 \mathrm{~mm}$ de comprimento total do corpo), presentes em todos os continentes, com exceção da Antártica, e particularmente abundantes na região Neotropical (WSC, 2018). Nos últimos anos, houve um significativo aumento do conhecimento taxonômico dos ctenídeos da América do Sul e, em especial, do Brasil Polotow \& Brescovit, 2008; 2009; 2013; Hazzi et al., 2013). Dentre as 15 espécies de ctenídeos do gênero Isoctenus descritas, apenas uma possui uma distribuição mais ampla, do Brasil até a Argentina. As demais espécies são restritas ao território brasileiro, todas de pequeno a médio porte (de 6,40 a 22,90), carapaça piriforme e olhos ctenóides no padrão 2-4-2 (Polotow \& Brescovit, 2009).

Dentre os métodos atualmente utilizados para a descrição de espécies, no presente projeto utilizou - se de figuras, medidas e caracteres diagnósticos para a descrição de 5 novas espécies a serem integradas ao gênero Isoctenus,

\section{Resultados e Discussão}

O material examinado foi depositado na coleção de aracnídeos do Instituito Butantan (IBSP, curador: Antonio D. Brescovit) e foram coletados entre os anos de 2000 a 2010. As amostras foram analisadas e agrupadas em prováveis morfoespécies e machos e fêmeas tiveram regiões e estruturas de importância taxonômica fotografadas, pela lupa Leica M165C. As fotos foram utilizadas, posteriormente, para a diferenciação e identificação de espécies de aranhas da família Ctenidae encontradas nas seguintes localidades: das seguintes localidades: Parque Nacional da Serra do Cipó (MG), Parque Nacional Municipal da Serra do Itapeti (SP), Piraputanga - Dois Irmãos do Buriti (MS), Reserva da Mata do Pau Ferro (PB) e Toca da Esperança (BA).

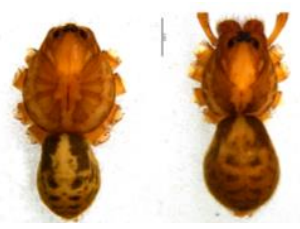

Figura 1. Vista dorsal de macho (esquerda) e fêmea (direita) evidenciando carapaça piriforme, padrão de olhos (2-4-2) e tamanho médio (aprox. 12mm).

\section{Conclusões}

Esta pesquisa demonstra uma potencial diversidade de aracnídeos ainda não conhecida em biomas como o Cerrado e Mata Atlântica, de modo a evidenciar a necessidade de mais estudos na área.

\section{Agradecimentos}

Declaro agradecimento ao Museu de Zoologia da Unicamp (ZUEC) pelo local de trabalho ao longo do projeto, além da FAPESP (processo 2015/22000-8) por todo suporte fornecido, bem como ao curador Antonio D. Brescovit.

1 World Spider Catalog (2018). World Spider Catalog. Natural History Museum Bern, online at http://wsc.nmbe.ch, version 19.0, accessed on April, 2018.

2 Polotow, D. \& Brescovit, A. D.; Revision of the Neotr Revision of the Neotropical spider genus Gephyroctenus octenus (Araneae: Ctenidae: Ctenidae: Calocteninae). Revista Brasileira de Zoologia, v. 25, 705-715, 2008.

3 Polotow, D. \& Brescovit, A.D. (2009a) Revision and cladistic analysis of Isoctenus and description of a new neotropical genus (Araneae, Ctenidae, Cteninae). Zoological journal of the Linnean Society, 583-314.

4 Polotow, D. \& Brescovit, A. D.; New species of the Neotropical spider genus Celaetycheus Simon, 1897 (Araneae: Ctenidae). Zootaxa, D, p.139-157, 2013.

5 Hazzi, N. A. et al. New records and geographical distribution of ctenid spiders (Araneae: Ctenidae) in Colombia. Zootaxa, n 49, 243-254, 2013. 